\title{
Electrocatalysis of the reduction of organic halide derivatives at modified electrodes coated by cobalt and iron macrocyclic complex-based films: application to the electrochemical determination of pollutants
}

\author{
A. Alatorre Ordaz ${ }^{1}$, J. Manriquez Rocha ${ }^{2}$, F. J. Acevedo Aguilar ${ }^{2}$, \\ S. Gutierrez Granados ${ }^{2}$ and F. Bedioui ${ }^{1 *}$ \\ ${ }^{1}$ Laboratoire d'Électrochimie et de Chimie Analytique (UMR $n^{\circ} 7575$ du CNRS), École Nationale Supérieure de \\ Chimie de Paris, 11, rue Pierre et Marie Curie, 75231 Paris Cedex 05, France \\ ${ }^{2}$ Instituto de Investigaciones Cientificas de la Universidad de Guanajuato, Cerro de la Venada S/N, \\ Pueblito de Rocha, 36040 Guanajuato, Mexico

\begin{abstract}
In this study, we go into the examination of the possible use of chemically modified electrodes by Hemin embedded in surfactant film of didodecyldimethylammonium bromide or by electropolymerized cobalt porphyrin and Salen films, as potential materials for the effective electrochemical detection of several organic halides (trichloroacetic acid, ethylene dibromide, tetrachloroethylene, trichloroethylene, dichloroacetic acid, 2,4,6-trichlorophenol, 2,4-dichlorophenoxy acetic acid, methoxychloride, etc.), in aqueous and organic solutions. The reported results show an important catalytic effect induced by the modification of the electrode surface by the metal complexes which is materialized by $1.0 \mathrm{~V}$ decrease in the reduction potential of the examined organic halide derivatives and a large increase in their reduction current (2 to 500 times). Our descriptive results of the electrocatalytic behaviour of the examined electrodes constitute a first important step in the investigation of the evaluation of a strategy materializing the use of these modified electrodes for the detection of various significant organohalide derivatives.
\end{abstract}

Keywords. Electrocatalysis - modified electrodes - detection - pollutants - complexes - organohalides.

\section{Introduction}

The extensive use of organochlorinated plaguicides in agriculture is an important source of water pollution provoking relevant ecological problems. Among the diverse plaguicides there are some derived from organic halides. These compounds are generally analyzed by liquid or gas chromatography and these analytical procedures can be improved by means of electrochemical sensors $[1,2]$. The fact is that the electrochemical reduction of organic halides is a kinetically slow process that requires high overpotentials. Nevertheless, electrochemically generated nucleophiles may rapidly reduce many organohalides [3] and improve the electrochemical reduction of such species. Thus, one alternative consists in immobilizing a redox catalyst on the electrochemical sensor surface.

Cobalt and iron porphyrins and metal Schiff base complexes are efficient catalysts for the electroreduction of various organic halide derivatives in homogeneous solution, and several examples have been reported in the literature showing the implication of $\mathrm{Co}(\mathrm{I})$ and $\mathrm{Fe}(\mathrm{I})$ redox state [4-9]. By immobilizing such complexes on the electrode surface, one may take profit from their electrocatalytic capabilities to conceive new analytical tools for the detection of organic halides in solution. Examples describing the use of modified electrodes based on porphyrin and Schiff base complexes, which have been immobilized by different physical ways (adsorption, chemical condensation or incorporation in an organic glue, electropolymerization) has been reported only recently [10-15].

For example, Root and coworkers [10] have pointed out the advantage of using a chemically modified electrode for the detection of organohalides by using a cobalt porphyrin adsorbed on the surface of a well-polished electrode. The flow injection analysis of 2,4-dichlorophenoxy acetic acid and 2,2-dichloroacetic acid showed that the response of the modified electrode was enhanced 50 times compared to the bare electrode. More recently, Dobson and Saini [11] reported the detection of different organohalides, including a number of industrial pollutants, by using a modified electrode consisting in a graphite foil covered with adsorbed cobalt porphyrin. The authors provided significant results on the detection of three classes of halides by amperometric measurements. They reported a detection limit of $0.5 \times 10^{-6} \mathrm{~mol} \times \mathrm{L}^{-1}$ for haloalkanes, 10 to $20 \times 10^{-6} \mathrm{~mol} \times \mathrm{L}^{-1}$ for haloalkenes and $30 \times 10^{-6} \mathrm{~mol} \times \mathrm{L}^{-1}$ 


\section{Original articles}

for haloarenes. It was also reported that the designed electrochemical devices were relatively insensitive to the ionic composition of the analyte samples and to the presence of oxygen.

Priyantha and Weerabahu [12] have also reported that iron(III) porphyrin-membrane coated electrode possesses a real catalytic activity for reduction of 3,4-dichloropropylanilide (an active ingredient of the herbicide propanil). Therefore, the authors constructed an electrochemical sensor which provides reproducible response at low concentration ranges with a detection limit of $8 \times 10^{-5} \mathrm{~mol} \times \mathrm{L}^{-1}$. The useful lifetime of the sensor is about seven weeks. In our group, we have demonstrated that the electroreduction of trichloroacetic acid can be improved by using a carbon electrode modified by electropolymerization of a pyrrole-cobaltporphyrin [13]. The reported results showed that the stability of the electropolymerized electrode was largely enhanced compared to that of the membrane electrodes and provide a powerful way to develop this approach towards the design of an analytical tool for the detection of trichloroacetic acid.

Finally, Rusling and coworkers [14] reported the catalytic reduction of organohalides using a membrane-like surfactant films of myoglobin and didodecyldimethylammonium bromide. The reduction reactions of the studied organohalogenated derivatives occurs at potentials about one volt more positive than the corresponding ones on a bare electrode. The rates of the electroacatalytic reactions were enhanced by preconcentration of the organohalides in the film. Despite the fact that they did not explicitely directed their study towards the detection of the examined organohalides, the authors pointed out that their results could be applied to the design of suitable electrochemical sensors. In our group, we have recently extented this approach to the detection of various organic halide derivatives and discussed the possible use of such modified electrodes in electroanalysis [15].

The aim of the present work is to extend the application of cobalt and iron porphyrin and Schiff base modified electrodes to more examples of organic halide derivative pollutants. We report here the study of the electrocatalytic behavior of electropolymerized $\mathrm{Co}(\mathrm{Salen})$ (Salen = bis(salicylidene)ethane-1,2-diamine) and CoTHPP (THPP = tetrakis (4-hydroxyphenyl) porphyrin) films in organic solvents and the electrocatalytic behavior of DDAB incorporated Hemin surfactant film (DDAB = didodecyldimethylammonium bromide; Hemin $=\mathrm{Cl}-\mathrm{Fe}(\mathrm{III})$ protoporphyrin IX) in aqueous solution towards some significant examples of organic halides, such as trichloroacetic acid (TCA), ethylene dibromide (EDB), tetrachloroethylene (PCE), trichloroethylene (TCE), dichloroacetic acid (DCA), 2-bromooctane (2BO), hexachlorobutadiene (HCB), $p$ dichlorobenzene (DCB), 2,4,6-trichlorophenol (2,4,6-T), 2,4dichlorophenoxy acetic acid (2,4-D), chloroform (CF), hexachlorocyclopentadiene (HCCPD), bromodichloromethane (BDCM) and methoxychloride (MC).

\section{Experimental}

\section{Electrochemical instrumentation and procedures}

The working electrodes were either highly oriented pyrolitic graphite HOPG (from Union Carbide Corp., USA) of $1 \mathrm{~cm}^{2}$ area or vitreous carbon disk VC (from Radiometer Tacussel, France) of $0.071 \mathrm{~cm}^{2}$ or indium tin oxide ITO (from Solems, France) of $1.9 \mathrm{~cm}^{2}$ area. The plane HOPG electrodes were easily cleaned before each experiment by removing the superficial layers of graphite with adhesive tape. The VC disk electrodes were polished with alumina pastes $(1,0.3$ and $0.05 \mu \mathrm{m})$ prior to experiments and ITO electrodes were rinsed with acetone and ultra pure milliQ water before each use. The potentials were measured with reference to the saturated calomel electrode (SCE). All the experiments were performed at room temperature, under nitrogen or argon atmosphere, with a PC-controlled potentiostatic system (model 263A from Applied Research Inc., USA or DEA 322/interface 101 from Radiometer-Tacussel, France). Cyclic voltammetry was performed with a potential sweep rate of $100 \mathrm{mV} / \mathrm{s}$. Differentiel pulse voltammetry was performed with a potential sweep rate of $20 \mathrm{mV} / \mathrm{s}$ (pulse height $=20 \mathrm{mV}$ and pulse width $=150 \mathrm{~ms}$ ). Square wave voltammetry was performed with potential sweep rate of $100 \mathrm{mV} / \mathrm{s}$ (pulse height $=25 \mathrm{mV}$, step height $=10 \mathrm{mV}$ and frequency $=10 \mathrm{~Hz}$ ).

DDAB/Hemin surfactant films were prepared according to previously reported method [15]: DDAB suspension $\left(10 \mathrm{mmol} \times \mathrm{L}^{-1}\right)$ in ultra pure milliQ water was ultrasonicated for 5 hours to produce homogeneous vesicle dispersion. Equal volumes of this vesicle dispersion and $0.5 \mathrm{mmol} \times \mathrm{L}^{-1}$ Hemin in acetate buffer solution $(\mathrm{pH}=5.6)$ were mixed and $40 \mu \mathrm{L} / \mathrm{cm}^{2}$ of this mixture were spread onto electrode surfaces and allowed to dry at room temperature for 12 hours to give a film of $c a .1 \mu \mathrm{m}$ thickness [16] containing $10 \mathrm{nmol} \times \mathrm{cm}^{-2}$ of Hemin.

Electrochemical deposition poly(CoSalen) film was achieved on vitreous carbon electrodes in acetonitrile $+0.1 \mathrm{~mol} \times \mathrm{L}^{-1} \mathrm{Bu}_{4} \mathrm{NBF}_{4}$ solution containing $1 \mathrm{mmol} \times \mathrm{L}^{-1}$ CoSalen by repeated potential scans between -1.8 and +1.7 $\mathrm{V} / \mathrm{SCE}$ (at $100 \mathrm{mV} / \mathrm{s}$ ), as previously reported [17]. The apparent surface coverages of the film electrode by CoSalen $\left(\mathrm{mol} \times \mathrm{cm}^{-2}\right)$ can be calculated from the cyclic voltammogram of the film (after transfer of the film, through careful rinsing, to a fresh acetonitrile solution containing no monomer), and the calculation is based on the charge under the oxidative or reductive peaks observed at $c a$. $-1.4 \mathrm{~V}$, related to the $\mathrm{Co}(\mathrm{II}) / \mathrm{Co}(\mathrm{I})$ redox process. In our considered case, poly(CoSalen) films were prepared by 3 repeated potential scans and this leads to the deposition of $1.65 \times 10^{-10} \mathrm{~mol} \times \mathrm{cm}^{-2}$ of CoSalen. This corresponds approximately to a film thickness of $2.4 \mathrm{~nm}$ [18].

Electrochemical deposition of poly(CoTHPP) film was achieved on ITO electrodes according to a similar procedure than above. In this case, poly(CoTHPP) films were prepared by 5 repeated potential scans (at $100 \mathrm{mV} / \mathrm{s}$ ) and this leads 


\section{Original articles}

to the deposition of $3.17 \times 10^{-10} \mathrm{~mol} \times \mathrm{cm}^{-2}$ of CoTHPP and a film thickness of $4.6 \mathrm{~nm}$ approximately [18].

\section{Chemicals}

CoSalen and Hemin complexes were from Aldrich and they were used as received. The insertion of $\mathrm{Co}$ (II) into the free porphyrin base tetrakis (4-hydroxyphenyl)porphyrin (Adrich) giving CoTHPP was carried out as previously reported [19]. All other chemical products were reagent grade (from Aldrich) and used as received.

\section{Results and discussion}

\section{Electrochemical activation of organic halides in aqueous solution}

Figure 1 shows the cyclic voltammograms of DDAB/Hemin modified electrode in acetate buffer solution $+50 \mathrm{mmol} \times \mathrm{L}^{-1} \mathrm{NaBr}$. The two well-defined couples of peaks located at approximately $\mathrm{E}_{\mathrm{eq}(1)}=-0.15 \mathrm{~V} / \mathrm{SCE}$ and $\mathrm{E}_{\mathrm{eq}(2)}=-1.10 \mathrm{~V} / \mathrm{SCE}\left(\mathrm{E}_{\mathrm{eq}}=\left(\mathrm{E}_{\mathrm{pa}}+\mathrm{E}_{\mathrm{pc}}\right) / 2, \mathrm{E}_{\mathrm{pa}}\right.$ and $\mathrm{E}_{\mathrm{pc}}$ are the potential values of the anodic and the cathodic voltammetric peaks for each redox process) can be related to $\mathrm{Fe}(\mathrm{III}) / \mathrm{Fe}(\mathrm{II})$ and $\mathrm{Fe}(\mathrm{II}) / \mathrm{Fe}(\mathrm{I})$ redox processes of the emdebbed Hemin, respectively (note that the cyclic voltamperogram shown here is the second repeated one recorded after the immersion of the electrode in the solution). It is important to note that the observed electroactivity of the entrapped Hemin remains stable and unchanged for hours (up to 8 hours) upon the immersion of the electrode in the electrolytic solution and/or repeated voltammetric scans if the potential range is restricted to $\mathrm{a}-1.3 \mathrm{~V}$ in the cathodic side. This tends to show that no loss of the entrapped complex is effective in the electrolytic solution, contrary to the previously reported observation by Nassar et al. [14].

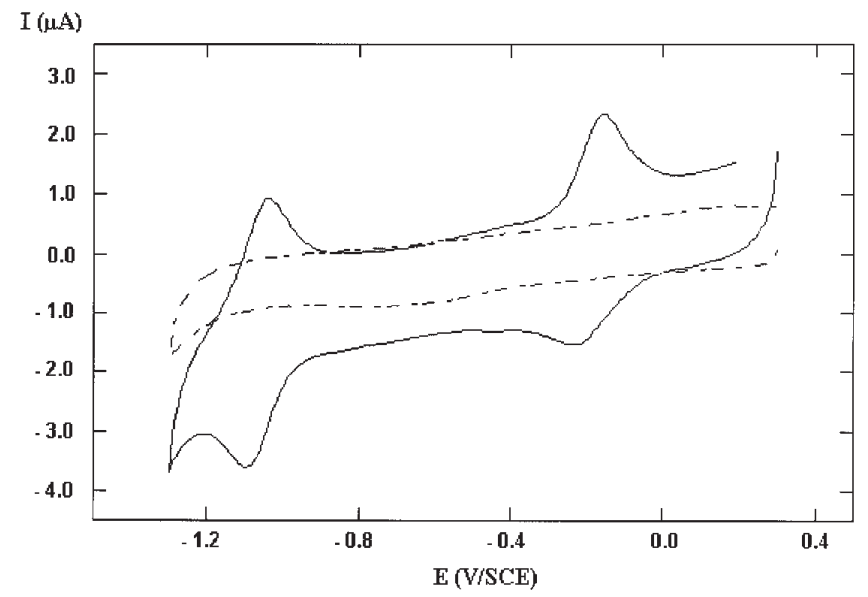

Figure 1. Cyclic voltammogram of DDAB/Hemin modified vitreous carbon electrode in aqueous acetate buffer solution containing $50 \mathrm{mmol} \times \mathrm{L}^{-1} \mathrm{NaBr}(\mathrm{pH}=5.6)$. Dashed curve is obtained with DDAB free Hemin film.
Figure 2 shows the square wave voltammograms obtained with DDAB/Hemin modified electrode in acetate buffer solution $(\mathrm{pH}=5.6)$ in the presence of TCA (Fig. 2a) and DCA (Fig. 2b). In these conditions, a large reduction current is developed at $c a$. $-1.1 \mathrm{~V}$. The figure shows also that the intensity of the observed current increases with TCA or DCA concentration in solution. This means that the $\mathrm{Fe}(\mathrm{II}) / \mathrm{Fe}(\mathrm{I})$ redox couple of the embedded Hemin is involved in the catalytic reduction of TCA and DCA. The catalytic process can be related to an outer-sphere mechanism in which the electron transfer takes place between the active form of the reduced Hemin $[\mathrm{Fe}(\mathrm{I})]$ and the organic halide, as previously suggested and analyzed by cyclic voltammetry $[14,15]$. It should be noted that the reduction of TCA and DCA on DDAB modified electrodes (without
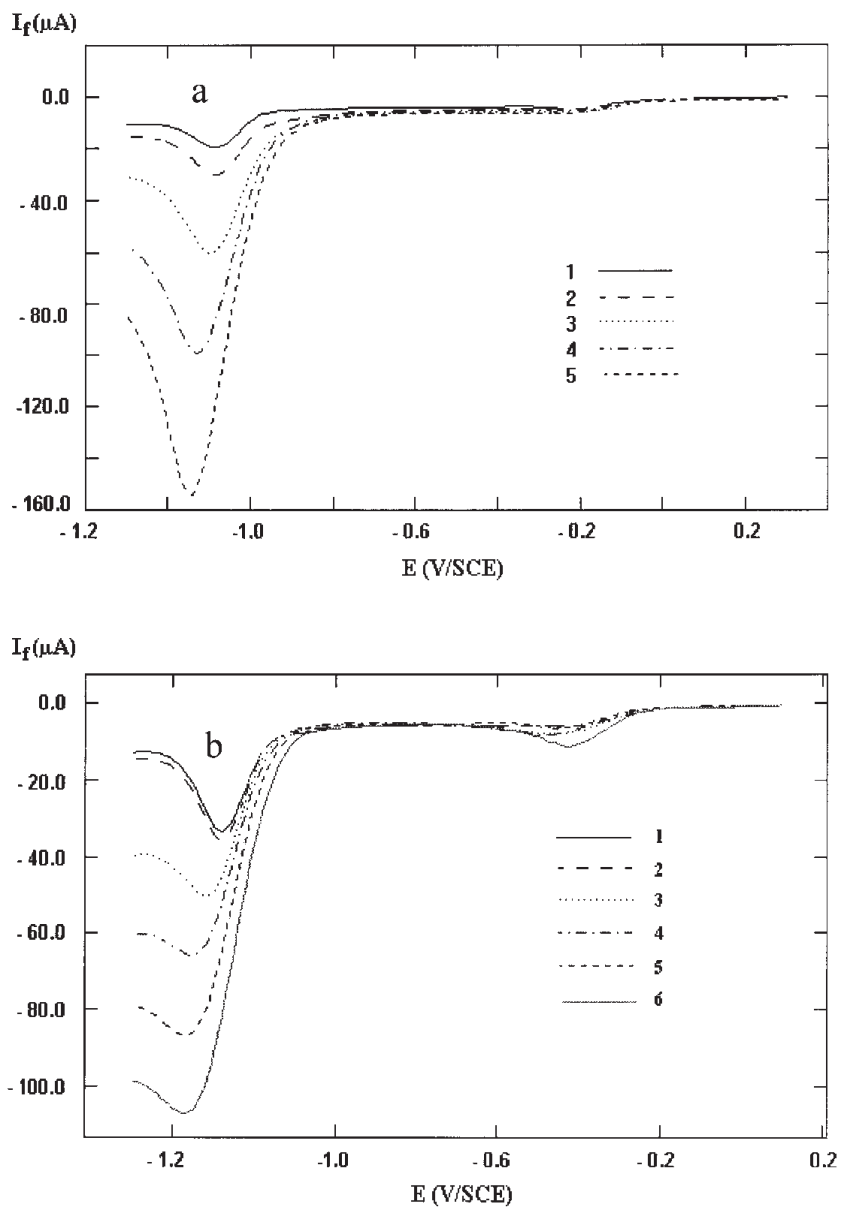

Figure 2. Square wave voltammograms of DDAB/Hemin modified vitreous carbon electrode in aqueous acetate buffer solution $+50 \mathrm{mmol} \times \mathrm{L}^{-1} \mathrm{NaBr}(\mathrm{pH}=5.6)$ containing

(a) TCA (1: $[\mathrm{TCA}]=0 ; 2:[\mathrm{TCA}]=0.1 \mathrm{mmol} \times \mathrm{L}^{-1}$;

3: $[\mathrm{TCA}]=0.3 \mathrm{mmol} \times \mathrm{L}^{-1} ; 4:[\mathrm{TCA}]=0.5 \mathrm{mmol} \times \mathrm{L}^{-1}$ and 5 : $\left.[\mathrm{TCA}]=0.8 \mathrm{mmol} \times \mathrm{L}^{-1}\right)$ and

(b) DCA (1: $[\mathrm{DCA}]=0 ; 2$ : $[\mathrm{DCA}]=0.2 \mathrm{mmol} \times \mathrm{L}^{-1}$;

3: $[\mathrm{DCA}]=0.4 \mathrm{mmol} \times \mathrm{L}^{-1}, 4:[\mathrm{DCA}]=0.6 \mathrm{mmol} \times \mathrm{L}^{-1}$;

5: $[\mathrm{DCA}]=0.8 \mathrm{mmol} \times \mathrm{L}^{-1}$ and $\left.6:[\mathrm{DCA}]=1 \mathrm{mmol} \times \mathrm{L}^{-1}\right)$. 
Hemin) occurs at $c a$. $-1.7 \mathrm{~V} / \mathrm{SCE}$. This result confirms that previously reported in the literature with an HOPG electrode modified by $\mathrm{DDAB} / \mathrm{Hb}$ or $\mathrm{DDAB} / \mathrm{Mb}$ films [15] ( $\mathrm{Hb}$ and $\mathrm{Mb}$ are hemoglobin and myoglobin enzymes, respectively). Our results concerning the catalytic reduction of EDB, TCE and PCE by DDAB/Hemin are similar to those shown for TCA and DCA and suggested that in all these cases $\mathrm{Fe}(\mathrm{II}) / \mathrm{Fe}(\mathrm{I})$ redox process was involved at $c a$. $-1.1 \mathrm{~V}$. The electrocatalytic capabilities of DDAB/Hemin films towards the electroreduction of various organic halides in aqueous solution are reported in table I. It clearly appears from these results that besides the fact that the reduction potential of the organic halide derivatives is shifted to higher values, the current response of the modified electrodes is largely enhanced, 2 to 32 times, compared to the bare electrode.

The electrocatalytic reduction currents of TCA and DCA generated over DDAB/Hemin modified electrodes are found to be directly proportional to the concentration of the organohalides in solution (Fig. 3). It should be noted that the sensitivity of the examined DDAB/Hemin film towards TCA and DCA, in term of the slope of the linear variation of $\mathrm{I}_{\text {cat }} v s$ TCA and DCA concentration, is much higher than those previously reported for $\mathrm{DDAB} / \mathrm{Mb}$ and $\mathrm{DDAB} / \mathrm{Hb}$ biomembranes (2 to 21 times higher, [15]). The $\mathrm{I}_{\text {cat }}$ was calculated from the voltammograms shown in figure 2, after substracting the peak current for the $\mathrm{Fe}(\mathrm{II}) / \mathrm{Fe}(\mathrm{I})$ reduction process in the absence of the organic derivatives. In the case of TCE, PCE and EDB a sligth passivation of the modified electrode was observed during repeated potential scanning. Such passivation complications were mentioned in the literature, in the case of $\mathrm{DDAB} / \mathrm{Mb}$ and $\mathrm{DDAB} / \mathrm{Hb}$ films [15] suggesting that the reduction products of these organic halides alterate the redox activity of the complex. Finally, no catalytic reduction was observed for DCB in the same conditions.

\section{$\mathbf{I}_{\text {cat }}(\boldsymbol{\mu A})$}

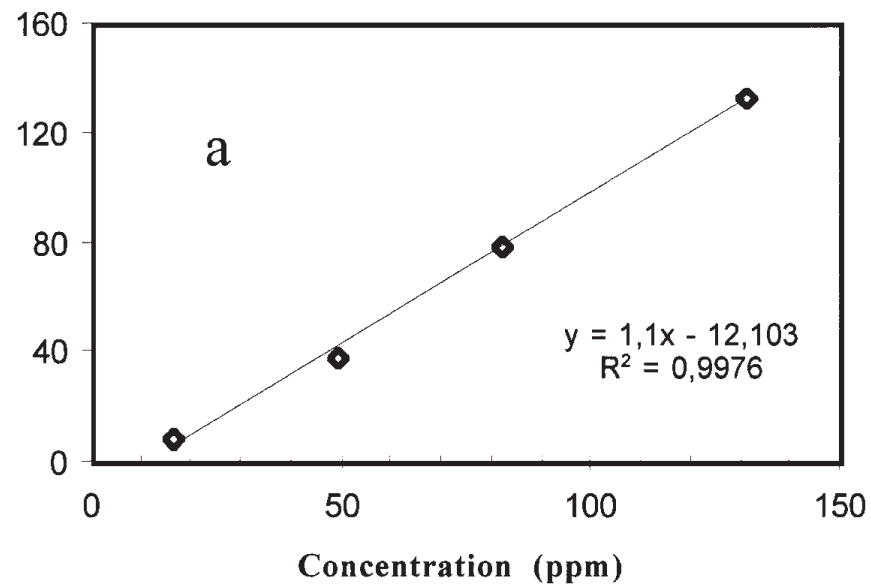

$\mathbf{I}_{\text {cat }}(\boldsymbol{\mu A})$

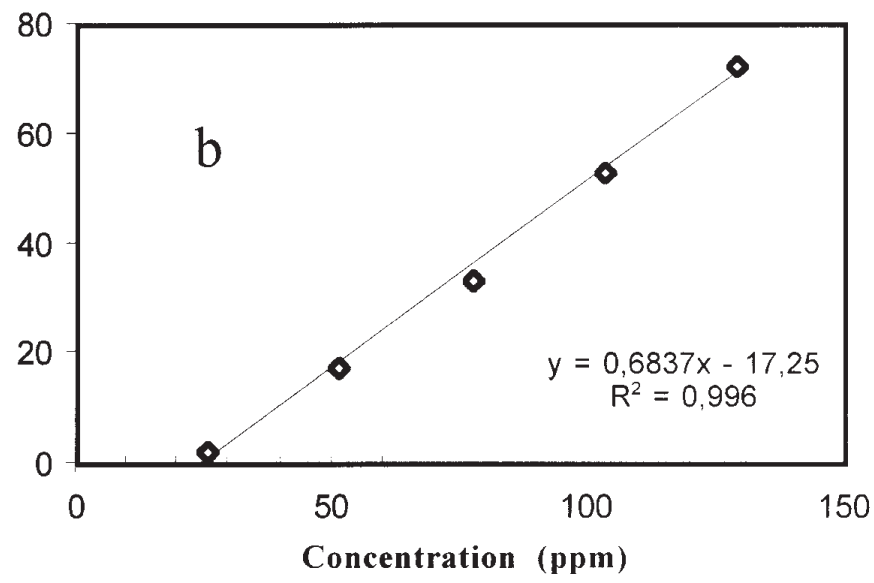

Figure 3. Variation of the catalytic reduction current $I_{\text {cat }}$, measured at $-1.1 \mathrm{~V}$ (from data like those shown in figure 2) with the concentration of TCA (curve a) and DCA (curve b) in aqueous acetate buffer solution $+50 \mathrm{mmol} \times \mathrm{L}^{-1} \mathrm{NaBr}(\mathrm{pH}=5.6)$.

Table I. Electrocatalysis data of the reduction of the various studied organic halides by DDAB/Hemin film in aqueous acetic buffer solution containing $50 \mathrm{mmol} \times \mathrm{L}^{-1} \mathrm{NaBr}(\mathrm{pH}=5.6)$.

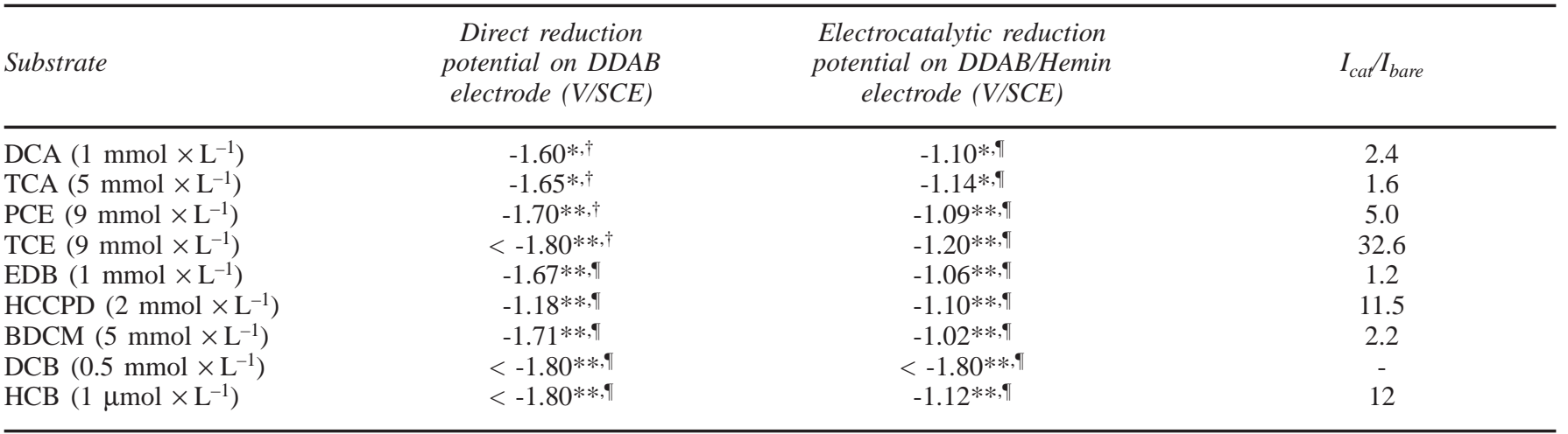

\footnotetext{
* square wave voltammetry; ** cyclic voltammetry; † vitreous carbon electrode; If highly oriented pyrrolitc graphite electrode
} 


\section{Original articles}

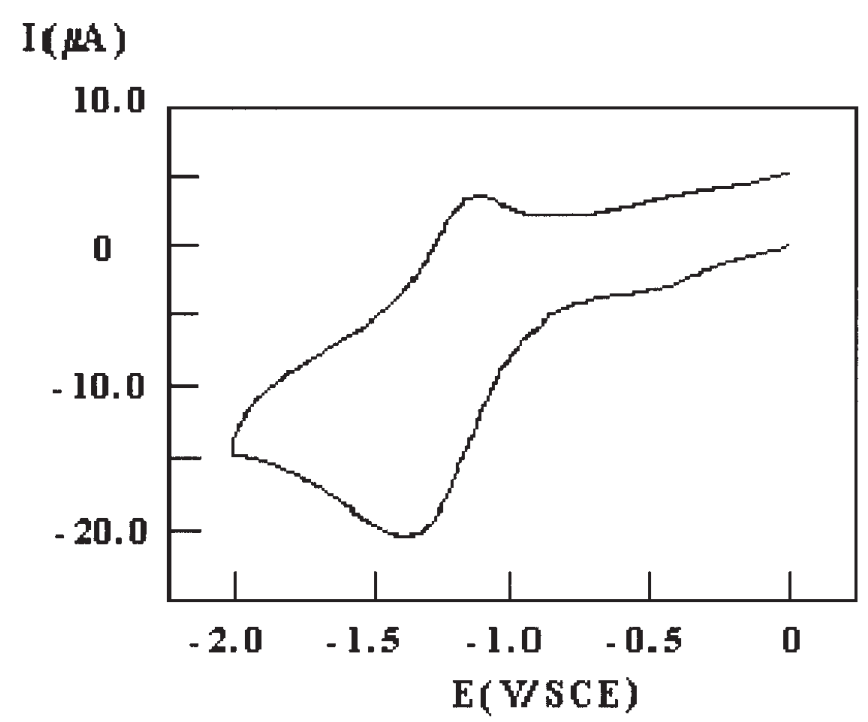

Figure 4. Cyclic voltammogram of poly(CoSalen) modified vitreous carbon electrode in acetonitrile $+0.1 \mathrm{~mol} \times \mathrm{L}^{-1} \mathrm{Bu}_{4} \mathrm{NBF}_{4}$ solution.

\section{Electrochemical activation of organic halides in acetonitrile solution}

Figure 4 shows the cyclic voltammogram of poly(CoSalen) modified electrode in acetonitrile $+0.1 \times$ mol L-1 $\mathrm{Bu}_{4} \mathrm{NBF}_{4}$ solution. The well-defined couple of peaks located at approximately $\mathrm{E}_{\mathrm{eq}}=-1.40 \mathrm{~V} / \mathrm{SCE}$ can be related to $\mathrm{Co}(\mathrm{II}) / \mathrm{Co}(\mathrm{I})$ redox process of the deposited complex. It is important to note that the observed electroactivity of poly(CoSalen) remains stable and unchanged for hours (up to 4 hours) upon the immersion of the electrode in the electrolytic solution and/or repeated voltammetric scans. Similar voltammograms were obtained with poly(CoTHPP) films in acetonitrile solution.

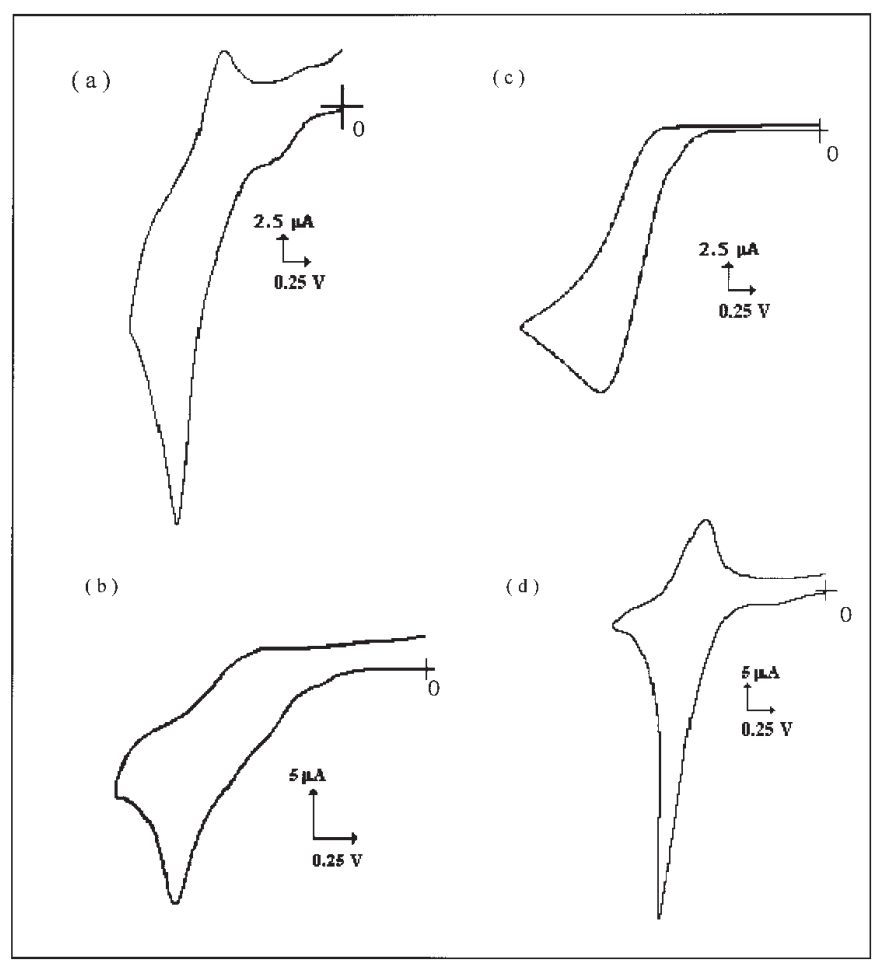

Figure 5. Cyclic voltammograms of poly(CoSalen) modified vitreous carbon electrode in acetonitrile $+0.1 \mathrm{~mol} \times \mathrm{L}^{-1} \mathrm{Bu}_{4} \mathrm{NBF}_{4}$ solution containing:

(a) $\mathrm{MC}$ : $59 \mu \mathrm{mol} \times \mathrm{L}^{-1}$; (b) TCE: $10 \mathrm{mmol} \times \mathrm{L}^{-1}$; (c) $\mathrm{EDB}$ : $10 \mathrm{mmol} \times \mathrm{L}^{-1}$ and (d) $2,4,6-\mathrm{T}$ : $20 \mathrm{mmol} \times \mathrm{L}^{-1}$.

Figure 5 shows the cyclic voltammograms obtained with poly $($ CoSalen) modified electrode in acetonitrile +0.1 mol $\times \mathrm{L}^{-1} \mathrm{Bu}_{4} \mathrm{NBF}_{4}$ solution in the presence of $\mathrm{MC}$ (curve a), TCE (curve b), EDB (curve c) and 2,4,6-T (curve d). In these conditions, a large reduction current is developed at $c a$.

Table II. Electrocatalysis data of the reduction of the various studied organic halides $\left(10 \mathrm{mmol} \times \mathrm{L}^{-1}\right)$ by poly $(\mathrm{CoSalen})$ and poly $(\mathrm{CoTHPP})$ films in acetonitrile $+0.1 \mathrm{M} \mathrm{Bu}_{4} \mathrm{NBF}_{4}$ solution.

\begin{tabular}{lccc}
\hline Substrate & $\begin{array}{c}\text { Direct reduction } \\
\text { potential on bare } \\
\text { electrode (V/SCE) }\end{array}$ & $\begin{array}{c}\text { Electrocatalytic reduction } \\
\text { potential on poly(Cosalen)* } \\
\text { or poly(CoTHPP)** } \\
\text { electrode }(\text { V/SCE) }\end{array}$ & $I_{\text {cal }} I_{\text {bare }}$ \\
\hline $2-$ BO & -2.52 & $-1.10^{*}$ & 103 \\
CF & -2.47 & $-1.50^{*}$ & 30 \\
EDB & -2.27 & $-1.47^{*}$ & 537 \\
HCB & -2.75 & $-1.02^{*}$ & 40 \\
$2,4,6-T$ & -2.62 & $-1.25^{*}$ & 17 \\
MC & -2.60 & $-1.55^{*}$ & 155 \\
PCE & -2.60 & $-1.16^{*}$ & 66 \\
TCE & -2.65 & $-1.60^{*}$ & 77 \\
$2,4-D$ & -2.10 & $-1.00^{* *}$ & 18 \\
\hline
\end{tabular}

*: cyclic voltammetry; **: differential pulse voltammetry 

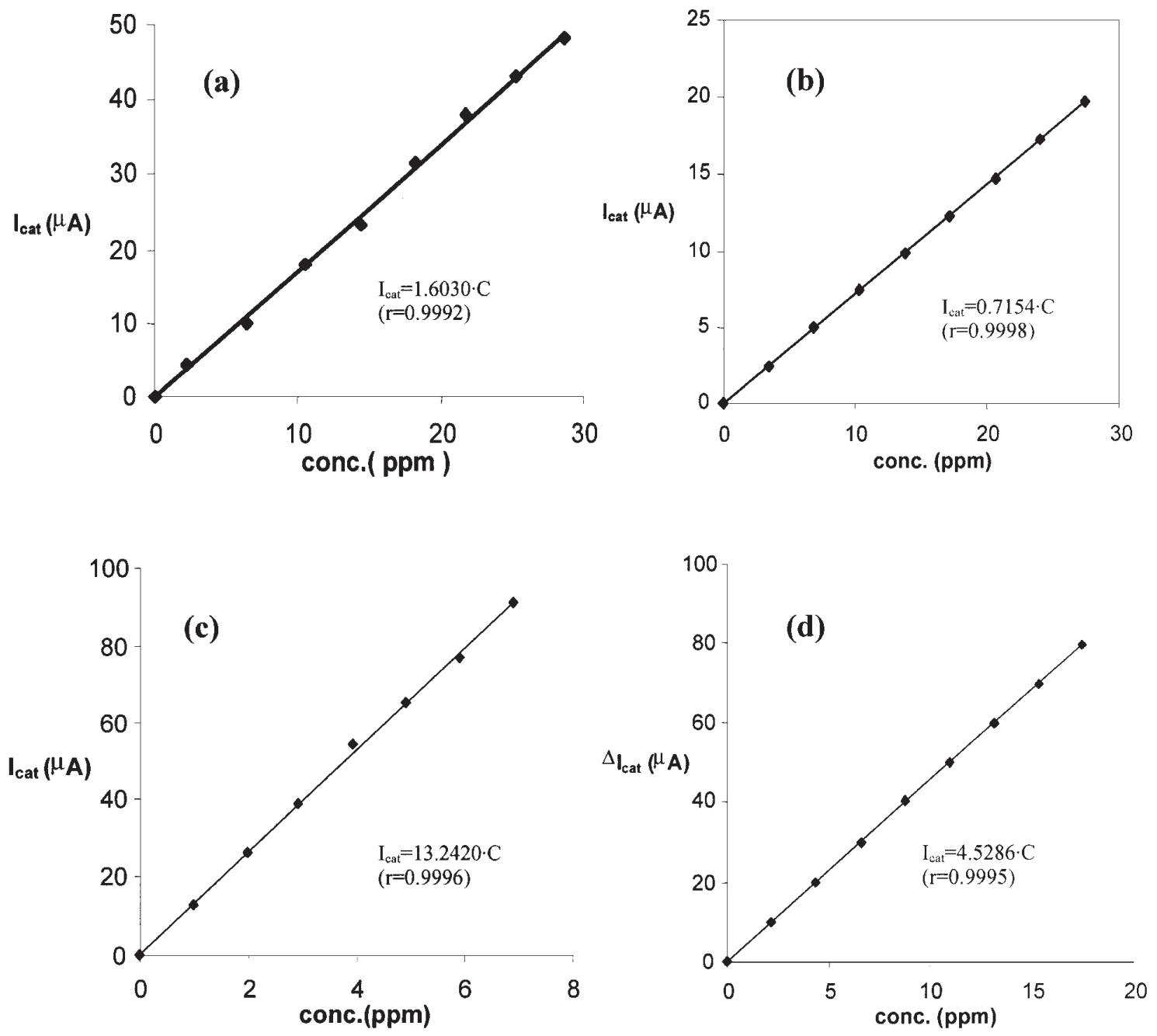

Figure 6. Variation of the catalytic reduction current, $\mathrm{I}_{\text {cat }}$, measured on poly $(\mathrm{CoSalen})$ modified electrode with the concentration of EDB (curve a); MC (curve b); 2,4,6-T (curve c) (measurements were made by cyclic voltammetry at $-1.47 \mathrm{~V},-1.57 \mathrm{~V}$ and $-1.50 \mathrm{~V}$, respectively) and on poly(CoTHPP) modified electrode and 2,4-D (curve d, measurement was made by differential pulse voltammetry at - $1.0 \mathrm{~V}$ ) in acetonitrile $+0.1 \mathrm{~mol} \times \mathrm{L}^{-1} \mathrm{Bu}_{4} \mathrm{NBF}_{4}$ solution.

$-1.2 \mathrm{~V}$. This means that the $\mathrm{Co}(\mathrm{II}) / \mathrm{Co}(\mathrm{I})$ redox couple of the electrodeposited CoSalen complex is involved in the catalytic reduction of examined organic halides, and the catalytic process can be related to an outer-sphere mechanism in which the electron transfer takes place between the active form of the reduced complex. It should be noted that the reduction of examined organic halides on unmodified electrodes (without CoSalen) occurs at $c a$. $-2.4 \mathrm{~V} / \mathrm{SCE}$. The electrocatalytic capabilities of poly(CoSalen) and poly(CoTHPP) films towards the electroreduction of various organic halides in acetonitrile solution are reported in table II. It clearly appears from these results that besides the fact that the reduction potential of the organic halide derivatives was shifted by more than $1 \mathrm{~V}$ to higher values, the current response of the modified electrodes was largely enhanced, 17 to 500 times, compared to the bare electrode.

The electrocatalytic reduction currents of EDB, MC and 2,4,6-T generated over poly(CoSalen) and 2,4-D generated over poly(CoTHPP) modified electrodes, respectively, are found to be directly proportional to the concentration of the organohalides in solution, as it is shown in figure 6. These electrodes offer a sensitivity of 1.06, 0.71, 13.24 and $4.52 \mathrm{ppm} / \mu \mathrm{A}$ ppm for $\mathrm{EDB}, \mathrm{MC}, 2,4,6-\mathrm{T}$ and $2,4-\mathrm{D}$, respectively. The calculated detection limits (signal-to-noise ratio 3) are $0.5 \mathrm{ppm}, 1.2 \mathrm{ppm}, 0.06 \mathrm{ppm}$ and $0.2 \mathrm{ppm}$ for EDB, MC, 2,4,6-T and 2,4-D, respectively. The experimentally determined quantification limits are $1.8 \mathrm{ppm}, 3.9 \mathrm{ppm}$, $0.2 \mathrm{ppm}$ and $0.6 \mathrm{ppm}$, respectively. It appears that 


\section{Original articles}

poly(CoSalen) modified electrode offers the highest performances (in term of sensitivity) towards 2, 4, 6-T.

\section{Conclusion}

Our descriptive results of the electrocatalytic behavior of DDAB/Hemin, poly(CoSalen) and poly(CoTHPP) films are new and they constitute one of the rare examples of application of such molecular materials in this field. They provide, for the first time, a clear insight into the investigation of the evaluation of a strategy materializing the use of these molecular materials for the detection of various significant organohalide derivatives, either in aqueous or in organic solution. This offers future prospects for coupling such chemically modified electrochemical sensors with liquid or gas chromatography analysis. These results also confirm the potentiality of the examined materials in the reductive dehalogenation process of organohalide derivatives.

\section{Acknowledgements}

Financial supports from ECOS (France)-SEP/ANUIES/ CONACYT (Mexico) program PM95B04 (travel expenses) and from University of Guanajuato (grant FOMES-SEP) are gratefully acknowledged. We thank Dr. C. Bied-Charreton (LPPSM, UMR n ${ }^{\circ} 8531$ du CNRS, ENS Cachan, France) for the metallation of THPP porphyrin.

\section{References}

1. Rajeshwar, K.; Ibanez J. Environmental Electrochemistry: Fundamentals and Applications in Pollution Abatement; Academic Press: San Diego, 1997.
2. Kissenger, P. T.; Heineman, W. R., Laboratory Techniques in Electroanalytical Chemistry; second edition, revised and expanded; Marcel Dekker: New York, 1996.

3. Steckhan, E. Angew. Chem. Int. Ed. Engl. 1986, 25, 683.

4. Lexa, D.; Saveant, J. M.; Soufflet, J.-P. J. Electroanal. Chem. 1979, 100, 159.

5. Guilard, R.; Kadish, M. Chem. Rev. 1988, 88, 1121.

6. Zheng, G.D.; Yan, Y.; Gao, S.; Tong, S.L.; Gao, D; Zhen, K.J. Electrochim. Acta 1996, 41, 177.

7. Elliott, C. M.; Maresse, C. A. J. Electroanal. Chem. 1981, 119, 395.

8. Bedioui, F.; Robin, Y.; Devynck, J.; Bied-Charreton, C. J. Organomet. Chem. 1987, 326, 117.

9. Duprilot, J.M.; Bedioui, F.; Devynck, J.; Folest, J. C.; BiedCharreton, C. J. Organomet. Chem. 1985, 286, 77.

10. Root, D. P.; Pitz, G.; Priyantha, N. Electrochim. Acta 1991, $36,5567$.

11. Dobson, D.J.; Saini, S. Anal. Chem. 1997, 69, 3532.

12. Priyantha, N.; Weerabahu, D. Anal. Chim. Acta 1996, 320, 263.

13. Vilchez-Aguado, F.; Gutiérrez Granados, S.; Sucar Succar, S.; Bied-Charreton, C.; Bedioui, F. New. J. Chem. 1997, 21, 1009.

14. Nassar, A. E.; Bobbit, J. M.; Stuart, J. D.; Rusling, J. F. J. Am. Chem. Soc. 1995, 117, 10986.

15. Alatorre Ordaz, A.; Bedioui, F. Sensors \& Actuators: Chemical B 1999, 59, 128.

16. Rusling, J. F.; Zhang, H. Langmuir 1991, 7, 1791.

17. Bedioui, F.; Labbé, E.; Gutierrez Granados, S.; Devynck, J. J. Electroanal. Chem. 1991, 301, 267.

18. Bedioui, F.; Voisin, M.; Devynck, J.; Bied-Charreton, C. J. Electroanal. Chem. 1991, 297, 257.

19. Adler, D. A.; Longo, F. R.; Kampas, F.; Kim, J. J. Inorg. Nucl. Chem. 1970, 32, 2443. 